\title{
Rapid multiplex high resolution melting method to analyze inflammatory related SNPs in preterm birth
}

\author{
Silvana Pereyra ${ }^{1,2}$, Tatiana Velazquez ${ }^{1}$, Bernardo Bertoni ${ }^{1}$ and Rossana Sapiro ${ }^{2 *}$
}

\begin{abstract}
Background: Complex traits like cancer, diabetes, obesity or schizophrenia arise from an intricate interaction between genetic and environmental factors. Complex disorders often cluster in families without a clear-cut pattern of inheritance. Genomic wide association studies focus on the detection of tens or hundreds individual markers contributing to complex diseases. In order to test if a subset of single nucleotide polymorphisms (SNPS) from candidate genes are associated to a condition of interest in a particular individual or group of people, new techniques are needed. High-resolution melting (HRM) analysis is a new method in which polymerase chain reaction (PCR) and mutations scanning are carried out simultaneously in a closed tube, making the procedure fast, inexpensive and easy. Preterm birth (PTB) is considered a complex disease, where genetic and environmental factors interact to carry out the delivery of a newborn before 37 weeks of gestation. It is accepted that inflammation plays an important role in pregnancy and PTB.

Methods: Here, we used real time-PCR followed by HRM analysis to simultaneously identify several gene variations involved in inflammatory pathways on preterm labor. SNPs from TLR4, IL6, IL1 beta and IL12RB genes were analyzed in a case-control study. The results were confirmed either by sequencing or by PCR followed by restriction fragment length polymorphism.

Results: We were able to simultaneously recognize the variations of four genes with similar accuracy than other methods. In order to obtain non-overlapping melting temperatures, the key step in this strategy was primer design. Genotypic frequencies found for each SNP are in concordance with those previously described in similar populations. None of the studied SNPs were associated with PTB.

Conclusions: Several gene variations related to the same inflammatory pathway were screened through a new flexible, fast and non expensive method with the purpose of analyzing their association to PTB. It can easily be used for simultaneously analyze any set of SNPs, either as the first choice for new association studies or as a complement to large-scale genotyping analysis. Given that inflammatory pathway is in the base of several diseases, it is potentially useful to analyze a broad range of disorders.
\end{abstract}

\section{Background}

Complex traits like cancer, diabetes, obesity or schizophrenia arise from an intricate interaction of genetic and environmental factors. Genetic bases of complex disorders are usually difficult to determine due to the fact that environmental factors such as life style and their epigenetic consequences are molding the

\footnotetext{
* Correspondence: rsapiro@fmed.edu.uy

${ }^{2}$ Departament of Histology and Embryology, School of Medicine, University

of the Republic, Gral. Flores 2125, Montevideo, Uruguay

Full list of author information is available at the end of the article
}

development of the disease. It is proposed that these factors mask the patterns of inheritance.

Preterm birth (PTB) is considered a complex disease, where genetics and environmental factors interact to lead to an undesirable effect which is the delivery of a newborn before 37 weeks of gestation [1,2]. PTB complicates many pregnancies and has for decades been strongly associated with increased risk of neonatal morbidity and mortality [3]. As a multifactorial trait, maternal stress, multiple pregnancies, exposure to toxics during pregnancy and genetic predisposition are well-

\section{Biomed Central}


known risk factors behind PTB [4]. It is also generally accepted that inflammation plays an important role in pregnancy and in PTB [5-7]. An altered inflammatory activity due to functionally relevant polymorphisms of the innate immune system may influence pathways leading to PTB and, therefore, impact on its frequency and/ or severity.

Post genomic era and high-throughput techniques like genome-wide association studies (GWAS) yield information on millions of single nucleotide polymorphisms (SNPs) distributed across the human genome, to indentify candidate genes involved in complex diseases $[8,9]$. Later, fewer SNPs should be replicated in different populations to confirm the results, implying the need of a middle throughput platform to fulfill the study requirements [10]. In addition, clinical applications after a GWAS should comprise testing the candidate SNPs in a particular individual or a small group of people. Thus, there is a pressing need for multi-SNP analysis methods that can reveal system-level differences in candidate patients that are suspected of suffering a particular condition.

Several SNP genotyping techniques had been developed, such as PCR followed by restriction fragment length polymorphism (RFLP), direct sequencing, or PCR-based TaqMan chemistry. Some of these techniques are either expensive or permit only one SNP per assay, meaning there are laborious and time-consuming.

High-resolution melting (HRM) analysis is a new and rapid method for mutation detection, in which polymerase chain reaction (PCR) and mutations scanning are carried out simultaneously in a single procedure [11]. Genotyping by high-resolution amplicon melting is achieved with a post-PCR short melting step and uses a next generation saturating double-stranded DNA binding dye. The amplicon melting profile depends on its length, GC content, sequence characteristics and heterozygosity. This approach provides a simple, closed-tube detection that can easily detect heteroduplexes as well as homoduplexes based on their characteristic melting curve profiles [12].

In the present study, we used HRM analysis to simultaneously identify mutations in four genes involved on inflammatory pathways. Genotype data from preterm newborns were compared to data acquired from those born at term. In particular, quadruplex amplicon genotyping by HRM analysis was developed to rapidly identify the allele frequencies of four SNPs related to inflammatory response.

\section{Methods}

\section{Study samples and DNA extraction}

Subjects in this study were unrelated offspring of women receiving obstetrical care at the Pereira Rossell
Hospital Center, Montevideo, Uruguay. Mothers with a history of drug abuse, chronic inflammatory diseases or twin pregnancy were excluded. The study protocol was approved by the School of Medicine's Ethics Committee of the University of the Republic, Uruguay. Mothers were inquired regarding sociodemographic characteristics, obstetric history, and data from the newborn through a specific designed questionnaire. Study population characteristics were previously detailed in Rey et al. [13]. Informed written consent was obtained from mothers prior to collection of biological material. Whole-blood samples from 56 subjects born at term and 53 born preterm were extracted and DNA isolated using DNeasy Blood and Tissue kit (Qiagen, Hilden, Germany). Each DNA sample was checked under an UV spectrophotometer (Biophotometa, Eppendorf, Hamburg, Germany).

\section{SNP selection, primer design and real time PCR conditions}

In order to test the capability of HRM analysis to distinguish variable types of SNPs, four different candidate genes were chosen based of several criteria: (1) SNPs that are common in the study population (minor allele frequency around 5\%-10\%), bearing in mind that ethnic variation in allele frequencies does exist; (2) SNPs with potential functional consequences (functional SNPs) that are likely to alter the expression levels (regulatory SNPs) or protein folding structure (non-synonymous SNPs); (3) SNPs that capture the variation across a gene and can be used later to assign a haplotype [14] and (4) SNPs with a potential role in the inflammatory cascade as well as interaction to environmental factors. The selected SNPs were: rs4986790 (Toll like receptor 4 (TLR4) gene), rs16944 (interleukin $1 \beta$ (IL-1 $\beta$ gene), rs1800795 (interleukin 6 (IL6) genes) and rs375947 (Interleukin 12 Receptor B (IL12RB) gene).

Several pairs of primer sets were designed for the aforementioned SNPs based in their flanking sequences using Primer3 tool (http://frodo.wi.mit.edu/ primer3/). We created amplicons with non-overlapping melting temperatures and smaller than $250 \mathrm{pb}$, to have higher sensibility in the HRM analysis. Following Seipp et al. [15] recommendations some of the primers were designed with the inclusion of either GCor AT-tails in order to modify the amplicon's melting temperature $(\mathrm{Tm})$.

\section{Real time PCR and high-resolution-melting analysis}

HRM analysis was performed on the Rotor-Gene $6000^{\mathrm{TM}}$ real-time instrument (Corbett Life Science, Sydney, Australia) with Eva Green, a saturating dye technology (Type-it HRM PCR Kit, Qiagen, Hilden, Germany). 
All oligonucleotides were first tested in a single oneamplicon reaction and then quadruplex amplification was optimized. To set up the multiplex reaction, primer concentrations were determined empirically. First, each amplicon was amplified individually using the same PCR conditions to identify its Tm and efficiency in genotyping with HRM. Secondly, multiplex HRM analysis was performed in equimolar concentrations of the four pair of primers. At last, primer concentrations were adjusted according to the size of the peak obtained: primers yielding amplicons with lowest peaks were augmented and vice-versa. In this way, primer concentrations were adjusted to equalize signal from all amplicons.

Finally, PCRs were performed in $10 \mu \mathrm{l}$ reaction volumes, containing 1X Qiagen HRM-typing buffer, 2.46 $\mu \mathrm{M}$ of each TLR4 gene primer, $0.46 \mu \mathrm{M}$ of each IL6 gene primer, $0.26 \mu \mathrm{M}$ of each IL1 $\beta$ gene primer, $0.9 \mu \mathrm{M}$ of each IL12RB gene primer and $25 \mathrm{ng}$ of template DNA. PCR reaction was carried out with an initial hold at $95^{\circ} \mathrm{C}$ for $5 \mathrm{~min}$, followed by 35 cycles of $95^{\circ} \mathrm{C}$ for $15 \mathrm{~s}$ and $60^{\circ} \mathrm{C}$ for $1 \mathrm{~min}$, and then HRM ramps were generated by acquiring fluorescence data at a temperature ramp from 72 to $88^{\circ} \mathrm{C}$. Individuals with homozygous and heterozygous genotypes were included as controls in all experiments.

HRM curves were normalized and genotype was assigned according to HRM curve shape by the RotorGene software and visual inspection. Melting curves observed were analyzed separately for each amplicon in the software to assign genotypes to samples.

\section{Restriction fragment length polymorphism (RFLP) and sequencing}

To corroborate genotype assignment, we performed a blinded study based on a subset of samples genotyped with PCR-RFLP assays. rs4986790 was analyzed using mismatched primers as described by Lorenz et al. [16]. rs16944 was analyzed according to Di Giovine et al. [17]. rs1800795 was amplified using same specific newly designed primer set employed in the real time PCR with the following conditions: $94^{\circ} \mathrm{C}$ for $5 \mathrm{~min}$, then 35 cycles of $94^{\circ} \mathrm{C}$ for $30 \mathrm{~s}, 62^{\circ} \mathrm{C}$ for $30 \mathrm{~s}, 72^{\circ} \mathrm{C}$ for $30 \mathrm{~s}$, and a final extension at $72^{\circ} \mathrm{C}$ for $5 \mathrm{~min}$. The products were digested with $5 \mathrm{U}$ of Hin1II (Fermentas Inc.) in a final volume of $20 \mu \mathrm{l}$ at $37^{\circ} \mathrm{C}$ for $2 \mathrm{~h}$. For rs375947 a modified protocol of Lee et al. [18] was employed, consisting in a double digestion with $5 \mathrm{U}$ of Hin $1 \mathrm{II}$ at $37^{\circ} \mathrm{C}$ for $2 \mathrm{~h}$ followed by a digestion with $10 \mathrm{U}$ of TaqI at $65^{\circ} \mathrm{C}$ for $12 \mathrm{~h}$. In all cases fragments were analyzed by electrophoresis on a $1.5 \%$ high-resolution agarose gel and stained with ethidium bromide for visualization.

A random subset of PCR samples for the four genes was also sequenced using the BigDye Direct Sequencing kit (Applied Biosystem).

\section{Statistical analyses}

All SNPs were tested for Hardy-Weinberg disequilibrium with an exact test. Case-control association tests were performed using $\chi^{2}$ test and the significance of associations between genotypes and PTB were assessed using logistic regression. Statistical analyses were performed with PLINK v1.07 [19].

\section{Results \\ HRM settings}

Designed conditions allowed obtaining a four-amplicon multiplex real-time PCR (Figure 1). The primers that best fitted conditions in order to obtain a four amplicon multiplex are indicated in Table 1. Temperature of melting (Tm) of amplicons is clearly separated from each other without overlap, spanning a $12^{\circ} \mathrm{C}$ temperature range. Amplicon with lowest $\mathrm{Tm}$ corresponds to rs4986790 $\left(\mathrm{Tm}=75.5^{\circ} \mathrm{C}\right)$, in which we found the homozygous genotype AA and heterozygous AG (Figure 2A). Second amplicon is rs 1800795 with $\mathrm{Tm}=78^{\circ} \mathrm{C}$ and only homozygous GG and heterozygous $\mathrm{CG}$ genotypes were found (Figure 2B). For rs16944 $\left(\mathrm{Tm}=83^{\circ} \mathrm{C}\right.$ ) (Figure 2C) and $\mathrm{rs} 375947\left(\mathrm{Tm}=85^{\circ} \mathrm{C}\right)$ (Figure 2D) all three genotypes where observed in each case.

\section{Genotype assignment}

rs4986790, rs1800795, rs16944 and rs375947 genotypes were correctly assigned from HRM curves observed in the Rotor-Gene software, using sequenced samples included as control genotypes as reference for assignment in all runs. Only 2 samples out of 109 could not be confidently genotyped by multiplex HRM in the case of rs375947 (Additional file 1).

Allelic frequencies were calculated for each SNP (Table 2). Hardy-Weinberg (H-W) disequilibrium exact test indicates that SNPs rs16944, rs4986790, rs1800795 are in Hardy-Weinberg equilibrium $(p>0.05)$, whereas rs375947, located in IL12RB gene, is not. Particularly, if case and control groups are discerned, H-W disequilibrium test for rs375947 indicates control individuals are in $\mathrm{H}-\mathrm{W}$ equilibrium, while case individuals are not (Table 2). No significant association was found between term and preterm newborns, for the analyzed SNPs $(p>$ 0.05; Table 2).

\section{Genotype verification}

The accuracy of the genotyping results was confirmed by RFLP and/or sequencing of the PCR product in a blinded study, for which random samples from our data study were used (Additional file 2). rs375947 (IL12RB) was assayed by means of a double digestion with restriction enzymes in a set of random individuals. The procedure was a modification of the strategy used by Lee et al. [18] and obtained a better 


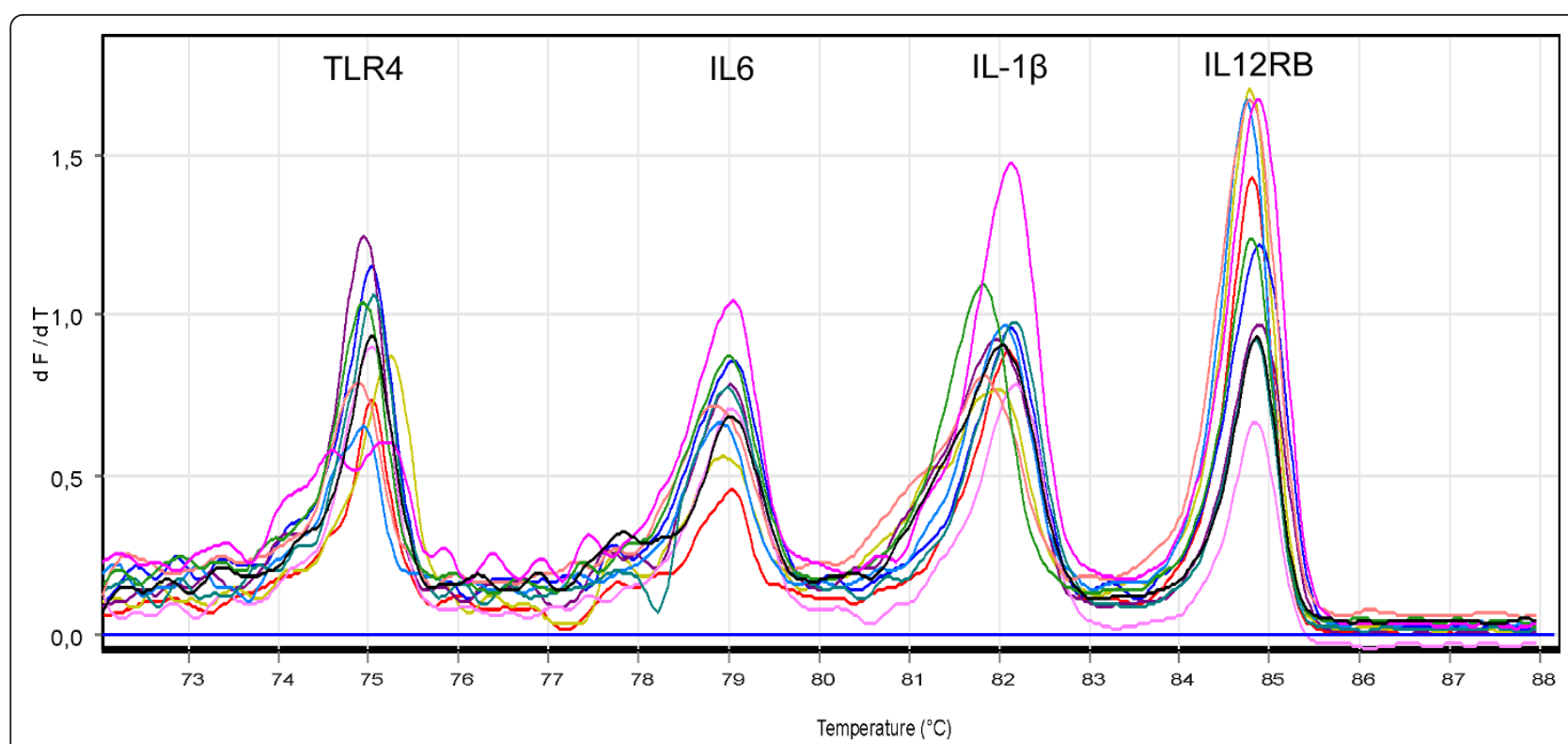

Figure 1 Representative quadruplex melting curves obtained by HRM. The melting peaks correspond to rs4986790 (TLR4), rs1800795 (IL6), rs16944 (IL-1B) and rs375947 (IL12RB) as temperature increases.

discrimination of the genetic variations. The rs375947 amplicon is a 487 bp length fragment and was digested with Hin1II and TaqI. The TaqI restriction site is localized at $311 \mathrm{bp}$ from the $5^{\prime}$ end. TaqI restriction site is a non polymorphic restriction site that allows distinguishing the fragments generated by Hin1II. When the 487 bp fragment is digested by Hin1II, a non polymorphic restriction site is localized at $243 \mathrm{bp}$ from the 5 ' end. A second Hin1II restriction site exists at 213 $\mathrm{pb}$ from the 5'end only at the SNP's mayor allele. After digestion with both enzymes, heterozygous SNPs yield a band pattern with 243, 216, 176, 68 and 27 bp fragments. Meanwhile, homozygotes are recognized because of the absence of the bands of 216 and $27 \mathrm{pb}$ in the case of GG genotype (band pattern: $243 \mathrm{pb}, 176$ $\mathrm{pb}$ and $68 \mathrm{pb}$ ); or the absence of $243 \mathrm{bp}$ in the case of AA (band pattern: $216 \mathrm{pb}, 176 \mathrm{pb}, 68 \mathrm{pb}$ and $27 \mathrm{pb}$ ) (Figure 3).

\section{Conditions that affected the efficiency of the multiplex PCR}

Design and concentration of primers proved to be the key step in this technique. Primers that generated amplicons between 50 to $250 \mathrm{bp}$ and that were designed to avoid having more than one SNP per amplicon got the higher HRM efficiency. Efficiency is defined by the ability to discern and call different genotypes. Amplicons with no-overlapping Tm's are an absolute requirement to be able to distinguish between the variants in a multiplex HRM analysis. In order to modify an amplicon's Tm it is more effective to design primers with varying lengths than to design modified primers. The inclusion of GC- or AT-tails in the primers (as in Seipp et al. [15]) did not notoriously affect amplicon's Tm in this particular multiplex.

As expected, quality and concentration of the DNA sample influenced multiplex efficiency. Software

Table 1 Primer sequences and amplicon information for the quadruplex HRM PCR assay

\begin{tabular}{|c|c|c|c|c|c|c|}
\hline \multirow{2}{*}{$\begin{array}{l}\text { SNP reference number } \\
\text { rs4986790 }\end{array}$} & \multirow{2}{*}{$\begin{array}{l}\text { Gene } \\
\text { TLR4 }\end{array}$} & \multirow{2}{*}{$\begin{array}{l}\text { Chromosome } \\
9\end{array}$} & \multicolumn{2}{|c|}{ Primer sequence $\left(5^{\prime}->3^{\prime}\right)$} & \multirow{2}{*}{$\begin{array}{l}\text { PCR product size (bp) } \\
157\end{array}$} & \multirow{2}{*}{$\begin{array}{l}\begin{array}{l}\text { Primer concentration } \\
\text { in multiplex PCR }(\mu \mathrm{M}\end{array} \\
2.46\end{array}$} \\
\hline & & & $\mathrm{F}$ & ATTTGACCATTGAAGAATTCCG & & \\
\hline & & & $\mathrm{R}$ & TGTTGCCATCCGAAATTATAAG & & \\
\hline \multirow[t]{2}{*}{ rs1800795 } & IL6 & 7 & $\mathrm{~F}$ & GCCTCAATGACGACCTAAGC & 105 & 0.46 \\
\hline & & & $\mathrm{R}$ & GGGGCTGATTGGAAACCTTA & & \\
\hline \multirow[t]{2}{*}{ rs16944 } & $\operatorname{IL} 1 \beta$ & 2 & F & CTTGGGTGCTGTTCTCTGCCTC & 126 & 0.26 \\
\hline & & & $\mathrm{R}$ & CAACTCCGTCAGGAGCCTGAAC & & \\
\hline \multirow[t]{2}{*}{ rs375947 } & IL12RB & 19 & $\mathrm{~F}$ & CTGCCATTCAATGCAATACG & 241 & 0.9 \\
\hline & & & $\mathrm{R}$ & CCCTGTAGGGTCAGGGGTAT & & \\
\hline
\end{tabular}




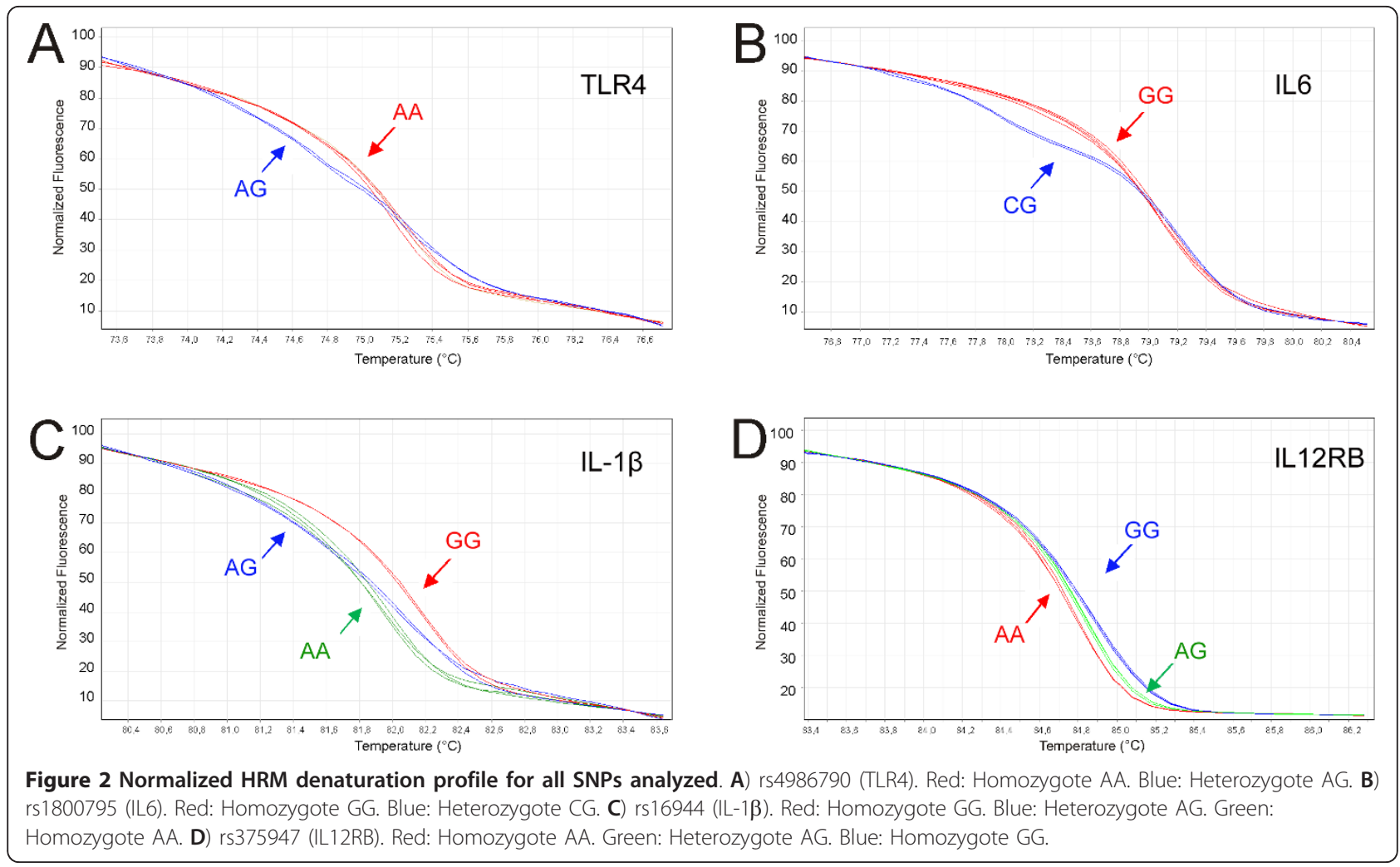

genotype assignment tool reached nearly $100 \%$ of accuracy when DNA sample had an OD 260/280 ratio within the normal range (1.8-2.0) and a concentration of $50 \mathrm{ng} /$ $\mu \mathrm{L}$ or higher. However, if some of these conditions were not met, the use of visual inspection of the curves allowed a correct assignment of the genotype in most cases.

Results can be viewed and genotype assigned as either a melting plot or a normalized difference plot as presented in the Rotor-Gene software, being the former one the most informative (Additional file 3).

\section{Discussion}

In this study, we developed a quadruplex real-time HRM -PCR test which allows rapid and reliable SNP genotyping. Applying this technique, we were able to efficiently genotype variations in four inflammationrelated genes at the same time in a case-control study population. The accuracy of the test was successfully verified through independent techniques such as PCRRFLP and/or sequencing.

Multiplex HRM strategy has many important advantages. Unlike conventional genotyping methods, this assay does not require post PCR manipulations, saving time and reducing contamination risk. In addition, in quadruplex amplification such as the one designed here, assay costs are greatly reduced by analyzing four SNPs simultaneously. We have also showed that common oligonucleotide pairs can be used in this analysis, hence reducing optimization time. Thus, additional modifications to change amplicon's Tm, as proposed by Seipp et al. [15], are not needed. Primer design is a key step in this strategy. Recently, a multiple SNP HRM genotyping assay was presented, but the authors measured different SNPs in the same amplicon [20]. In our case, we specifically avoided more than one SNP in each amplicon. Potentially, two SNPs could give 9 different combined signals for the same amplicon, distorting the other SNP

Table 2 Allelic frequencies for each analyzed SNP in cases and controls.

\begin{tabular}{lllllll}
\hline SNP & Minor allele & MAF in cases & MAF in controls & P-values HWE & OR & P-values OR \\
\hline rs4986790 & G & 0.0472 & 0.0179 & 1 & 2.81 & 0.2291 \\
rs1800795 & C & 0.1698 & 0.1429 & 0.0691 & 1.29 & 0.5441 \\
rs16944 & A & 0.3962 & 0.4018 & 0.4262 & 0.98 & 0.93 \\
rs375947 & G & 0.3023 & 0.3571 & 0.0002 & 0.84 & 0.5232 \\
\hline
\end{tabular}

Statistical significance for the Hardy-Weinberg test ( $\mathrm{p}$-value H-W equilibrium) and Odd Ratios (OR) based on a logistic regression. MAF: Minor Allele Frequency. 


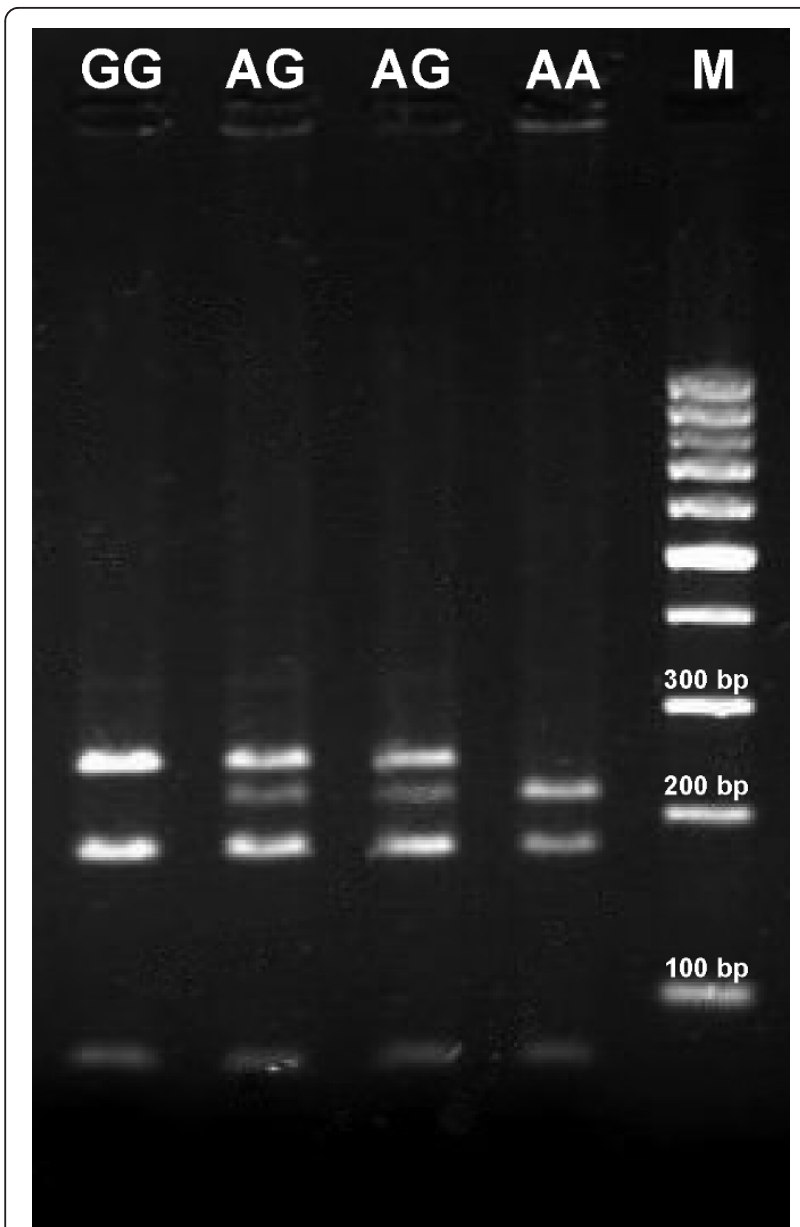

Figure 3 Digested rs375947 (IL12RB) electrophoresis patterns for each genotype. Genotypes are marked in each well. M: molecular weight marker.

signals in a quadruplex study. There is a limited range to separate curves in HRM from different amplicons and four SNPs seems to be the present limit for this technology $[21,22]$.

Rotor-Gene platform is commonly used to perform HRM analysis (e.g. [23,24]); however, no quadruplex amplification had been reported in this instrument. A quadruplex PCR was previously reported in the LightCycler-32 platform, but this could not be reproduced in other instruments [15]. Here, we have designed the first report of a multiplex HRM genotyping assay in a RotorGene platform.

Genotyping was straightforward in all SNPs, with homozygous HRM profiles differing from heterozygous in curve shape, while the different homozygotes being easily distinguished because of their Tm shift.

Interestingly, in this study we were not able to find some of the variants already reported by other authors. Namely, we were not able to identify the minor homozygote genotype (CC) for rs1800795 (IL6) or the GG genotype for rs4986790 (TLR4) in our study population. It is reported that it may be difficult to distinguish common homozygotes from rare homozygotes in HRM for some SNPs [24], which could explain this situation. However, we independently assayed a subset of samples with PCR-RFLP and/or sequencing, finding most genotyping calls identical to those made based on HRM results, suggesting that those variants are more likely not present in the analyzed subjects. The absence of such genotypes could be attributed to the limited sample size in our analysis, but could also be explained by different allele frequencies present here in comparison to other populations. Previously, Rey et al. [13] screened over 400 patients from a Uruguayan sample genotyping SNP rs4986790 (TLR4) without finding the rare homozygote, indicating this genotype is present in low frequency in this population. On the other hand, HAPMAP data revealed that rs 4986790 GG genotype is very rare in nearly all studied populations. Moreover, although the CC genotype for the rs1800795 (IL6) is present in $30 \%$ in the European population, it is absent in the Mexican population (Table 3). Uruguayan and Mexican populations have a similar genetic structure

Table 3 Genotype frequencies for each analyzed SNP in Europe (CEU), Japan (JPT), Yoruba (YRI), Mexican (MXC) populations and the Uruguayan sample *

\begin{tabular}{|c|c|c|c|c|c|}
\hline Population & SNP & Gene & Genotype & Genotype & Genotype \\
\hline & rs4986790 & TLR4 & $\mathrm{A} \mid \mathrm{A}$ & $A \mid G$ & $\mathrm{G} \mid \mathrm{G}$ \\
\hline CEU & & & 0.933 & 0.067 & \\
\hline JPT & & & 1 & & \\
\hline YRI & & & 0.933 & 0.067 & \\
\hline$M X C$ & & & 0.939 & 0.061 & \\
\hline \multirow[t]{2}{*}{ This study } & & & 0.936 & 0.064 & \\
\hline & rs1800795 & IL6 & $C \mid C$ & $C \mid G$ & $\mathrm{G} \mid \mathrm{G}$ \\
\hline CEU & & & 0.305 & 0.458 & 0.237 \\
\hline JPT & & & & & 1 \\
\hline YRI & & & & & 1 \\
\hline$M X C$ & & & & 0.320 & 0.680 \\
\hline \multirow[t]{2}{*}{ This study } & & & & 0.312 & 0.688 \\
\hline & rs16944 & IL1 $\beta$ & $\mathrm{A} \mid \mathrm{A}$ & $A \mid G$ & $\mathrm{G} \mid \mathrm{G}$ \\
\hline CEU & & & 0.145 & 0.4 & 0.455 \\
\hline JPT & & & 0.222 & 0.444 & 0.333 \\
\hline YRI & & & 0.321 & 0.491 & 0.189 \\
\hline$M X C$ & & & 0.240 & 0.520 & 0.240 \\
\hline \multirow[t]{2}{*}{ This study } & & & 0.138 & 0.523 & 0.339 \\
\hline & rs375947 & IL12RB & $\mathrm{A} \mid \mathrm{A}$ & $A \mid G$ & $\mathrm{G} \mid \mathrm{G}$ \\
\hline CEU & & & 0.383 & 0.483 & 0.133 \\
\hline JPT & & & 0.364 & 0.5 & 0.136 \\
\hline YRI & & & 0.567 & 0.4 & 0.033 \\
\hline$M X C$ & & & 0.720 & 0.280 & \\
\hline This study & & & 0.541 & 0.259 & 0.200 \\
\hline
\end{tabular}

\footnotetext{
* HapMap frequencies $<0.01$ are not indicated
} 
with contribution from Spaniards, Africans and Native Americans [25], which could be explaining the frequencies shown in Table 3. Taking all these data together, it is more likely that the absence of the rare homozygote in our study could be related to allele architecture in the population and not to HRM technical limitations.

The developed assay focuses on variants related to inflammatory pathways, involved in host defense mechanisms, innate immunity activation and infection, as indicated in some of the web-based reference databases that link the genome to biologic systems (Kyoto Encyclopedia of Genes and Genomes, http://www.genome.jp/kegg/pathway.html; http://www.genome.jp/keggbin/show_pathway?map04620). For instance, the nonsynonymous TLR4 SNP analyzed here (rs4986790) has been associated with differences in lipopolysaccharide responsiveness and predisposition to complex diseases like atherogenesis, respiratory dysfunction and preterm birth [26-29]. IL-6 -174 (rs1800795) G allele carriers produce higher levels of IL- 6 than those with the CC genotype, and have a higher prevalence of systemic juvenile-onset chronic arthritis, lipid abnormalities and insulin resistance [30,31]. Also, analyzed SNP in the IL-1 $\beta$ gene promoter (rs16944) affects IL- $1 \beta$ expression and is associated with increased risk of cancer and preterm birth [32,33]. The protein encoded by IL12RB gene is a type I transmembrane protein that belongs to the hemopoietin receptor superfamily. The lack of expression of this gene was found to result in the immunodeficiency of patients with severe mycobacterial and Salmonella infections [34], and particularly, the rs375947 SNP is associated with atopic dermatitis [35]. Likewise, using other biological databases which identify SNPs associated to a particular condition, this multiplex HRM method could be potentially applied to analyze the risk to suffer the trait of interest of both patients and populations.

Although over the last years, high-resolution SNP genotyping arrays have greatly facilitated the identification of major genetic risk factors underlying complex diseases, such major genes seem to be rare. Instead, there is growing evidence that rare alleles and evolutionarily short-lived mutations play a major role in the etiology of complex disorders, which seem to be far more heterogeneous than previously assumed [36]. Dissection of complex disorders into many separate entities could greatly increase the chances for understanding the underlying pathogenetic mechanisms; for example, by defining novel candidate genes that are part of the same pathway [36]. Given that inflammation has been implicated in the mechanisms responsible for preterm and term parturition [5,6], screening of the chosen SNPs is a reasonable strategy to understand both mechanisms. Even more, inflammatory and immunological aspects are postulated to be on the base of several complex diseases others than PTB like atherogenesis, cancer, metabolic affections, endocrinophatys and even obesity [37-39]. Thus, as SNPs selected here are situated in genes related to an inflammatory pathway, we describe a potential tool to confident and rapidly screen gene variations that are common to a broad range of disorders.

Multiplex analysis by HRM could also be an accurate and reliable method for mutation detection in known genes after the identification of particular variations through the powerful existing strategies for elucidating genetic variations, such as array methods, whole-genome screening for copy number variation and high-throughput and low-cost sequencing.

\section{Conclusions}

Several gene variations related to the same inflammatory pathway were screened with the purpose of analyzing their association to preterm birth. Multiplex HRM analysis has proved to be a flexible, fast and non expensive tool. It can easily be used for any set of SNPs, either as the first choice for new association studies or as a complement to largescale genotyping analysis. It should be considered as a reliable genotyping technique for low or middle throughput projects. At last, the developed method can now be employed to assay genetic associations to preterm birth through a larger scale population study.

\section{Additional material}

Additional file 1: Genotype call by HRM for all newborns. Multiplex HRM assigned data to all samples ND: no data.

Additional file 2: Subset of DNA samples genotyped by different techniques. Genotype assignment for each analyzed SNP by Multiplex HRM, RFLP and sequencing.

Additional file 3: Figure S1. A) Melting profile for rs16944 (IL1ß). Red: Homozygote GG. Blue: Heterozygote AG. Green: Homozygote AA. B) Normalized difference plot for rs16944 (IL1ß), genotype AG as a reference.

\section{List of Abbreviations}

SNPs: single nucleotide polymorphisms; HRM: High-resolution melting; PCR: polymerase chain reaction; PTB: Preterm birth; GWAS: genome-wide association studies; RFLP: restriction fragment length polymorphism; TLR4: Toll like receptor 4; IL-1B: Interleukin 1 3 ; IL6: Interleukin 6; IL12RB: Interleukin 12 Receptor B; H-W: Hardy-Weinberg; OR: Odd Ratios; MAF: Minor Allele Frequency; Tm: Temperature of melting; CEU: European population; JPT: Japanese population; YRI: Yoruba; MXC: Mexican population; ND: No data.

\section{Acknowledgements}

Funding for this work was provided by Fogarty International Center 'National Institutes of Health' grant RO1TW006223 and Comision Sectorial de Investigacion Cientifica (Uruguay). We acknowledge Drs. Justo Alonso Tellechea, Grazzia Rey and Daniel Grasso (Pereira Rossell Hospital Center) for their invaluable support in patient and control subject recruitment, Mrs. Souza, from Dickens Institute, for her careful review of manuscript language and $J$ Faluótico for his technical support. 


\section{Author details}

'Departament of Genetics, School of Medicine, University of the Republic, Gral. Flores 2125, Montevideo, Uruguay. ${ }^{2}$ Departament of Histology and Embryology, School of Medicine, University of the Republic, Gral. Flores 2125, Montevideo, Uruguay.

\section{Authors' contributions}

SP and TV designed HRM conditions, primers, and carried on molecular genetics experiments. SP, TV, BB and RS were involved in data analysis. BB and RS designed the study, and participated in its design and coordination. SP and BB performed statistical analyses. SP, BB and RS wrote the manuscript. All authors contributed to and have approved the final manuscript.

\section{Competing interests}

The authors declare that they have no competing interests.

Received: 3 October 2011 Accepted: 26 January 2012 Published: 26 January 2012

\section{References}

1. Goldenberg RL: The management of preterm labor. Obstet Gynecol 2002, 100:1020-1037.

2. Goldenberg RL, Culhane JF, lams JD, Romero R: Epidemiology and causes of preterm birth. Lancet 2008, 371:75-84.

3. Ananth CV, Vintzileos AM: Epidemiology of preterm birth and its clinical subtypes. J Matern Fetal Neonatal Med 2006, 19:773-782.

4. Goldenberg R, Culhane J, lams J, Romero R: Epidemiology and causes of preterm birth. Lancet 2008, 371:75-84.

5. Romero R, Espinoza J, Goncalves LF, Kusanovic JP, Friel L, Hassan S: The role of inflammation and infection in preterm birth. Semin Reprod Med 2007, 25:21-39.

6. Romero R, Espinoza J, Goncalves LF, Kusanovic JP, Friel LA, Nien JK: Inflammation in preterm and term labour and delivery. Semin Fetal Neonatal Med 2006, 11:317-326

7. Romero R, Espinoza J, Kusanovic J, Gotsch F, Hassan S, Erez O, Chaiworapongsa T, Mazor M: The preterm parturition syndrome. BJOG 2006, 113:17-42.

8. Hirschhorn JN, Daly MJ: Genome-wide association studies for common diseases and complex traits. Nat Rev Genet 2005, 6:95-108

9. McCarthy Ml, Abecasis GR, Cardon LR, Goldstein DB, Little J, loannidis JP, Hirschhorn JN: Genome-wide association studies for complex traits: consensus, uncertainty and challenges. Nat Rev Genet 2008, 9:356-369.

10. Chanock SJ, Manolio T, Boehnke M, Boerwinkle E, Hunter DJ, Thomas G, Hirschhorn JN, Abecasis G, Altshuler D, Bailey-Wilson JE, et al: Replicating genotype-phenotype associations. Nature 2007, 447:655-660

11. Reed GH, Kent JO, Wittwer CT: High-resolution DNA melting analysis for simple and efficient molecular diagnostics. Pharmacogenomics 2007, 8:597-608

12. Liew M, Pryor R, Palais R, Meadows C, Erali M, Lyon E, Wittwer C: Genotyping of Single-Nucleotide Polymorphisms by High-Resolution Melting of Small Amplicons. Clin Chem 2004, 50:1156-1164.

13. Rey G, Skowronek F, Alciaturi J, Alonso J, Bertoni B, Sapiro R: Toll receptor 4 Asp299Gly polymorphism and its association with preterm birth and premature rupture of membranes in a South American population. Mol Hum Reprod 2008, 14:555-559.

14. Pennell C, Jacobsson B, Williams S, Buus R, Muglia L, Dolan S, Morken N, Ozcelik H, Lye S, Relton C: Genetic epidemiologic studies of preterm birth: guidelines for research. Am J Obstet Gynecol 2007, 196:107-118.

15. Seipp MT, Pattison D, Durtschi JD, Jama M, Voelkerding KV, Wittwer CT: Quadruplex genotyping of F5, F2, and MTHFR variants in a single closed tube by high-resolution amplicon melting. Clin Chem 2008, 54:108-115.

16. Lorenz E, Frees KL, Schwartz DA: Determination of the TLR4 genotype using allele-specific PCR. Biotechniques 2001, 31:22-24.

17. di Giovine FS, Takhsh E, Blakemore Al, Duff GW: Single base polymorphism at -511 in the human interleukin-1 beta gene (IL1 beta). Hum Mol Genet $1992,1: 450$.

18. Lee HW, Lee HS, Kim DK, Ko DS, Han SK, Shim YS, Yim JJ: Lack of an association between interleukin-12 receptor beta1 polymorphisms and tuberculosis in Koreans. Respiration 2005, 72:365-368.
19. Purcell S, Cherny SS, Sham PC: Genetic Power Calculator: design of linkage and association genetic mapping studies of complex traits. Bioinformatics 2003, 19:149-150.

20. Levesque S, Michaud S, Arbeit RD, Frost EH: High-resolution melting system to perform multilocus sequence typing of Campylobacter jejuni. PLoS One 2011, 6:e16167.

21. Krypuy M, Newnham GM, Thomas DM, Conron M, Dobrovic A: High resolution melting analysis for the rapid and sensitive detection of mutations in clinical samples: KRAS codon 12 and 13 mutations in nonsmall cell lung cancer. BMC Cancer 2006, 6:295.

22. Seipp MT, Durtschi JD, Voelkerding KV, Wittwer CT: Multiplex amplicon genotyping by high-resolution melting. J Biomol Tech 2009, 20:160-164.

23. Vossen RH, Aten E, Roos A, den Dunnen JT: High-resolution melting analysis (HRMA): more than just sequence variant screening. Hum Mutat 2009, 30:860-866.

24. Garritano S, Gemignani F, Voegele C, Nguyen-Dumont T, Le Calvez-Kelm F, De Silva D, Lesueur F, Landi S, Tavtigian SV: Determining the effectiveness of High Resolution Melting analysis for SNP genotyping and mutation scanning at the TP53 locus. BMC Genet 2009, 10:5.

25. Sans M: Admixture studies in Latin America: from the 20th to the 21st century. Hum Biol 2000, 72:155-177

26. Arbour NC, Lorenz E, Schutte BC, Zabner J, Kline JN, Jones M, Frees K, Watt JL, Schwartz DA: TLR4 mutations are associated with endotoxin hyporesponsiveness in humans. Nat Genet 2000, 25:187-191.

27. Kiechl S, Lorenz E, Reindl M, Wiedermann CJ, Oberhollenzer F, Bonora E, Willeit J, Schwartz DA: Toll-like receptor 4 polymorphisms and atherogenesis. N Engl J Med 2002, 347:185-192.

28. Lorenz E, Hallman M, Marttila R, Haataja R, Schwartz DA: Association between the Asp299Gly polymorphisms in the Toll-like receptor 4 and premature births in the Finnish population. Pediatr Res 2002, 52:373-376.

29. Reindl M, Lutterotti A, Ingram J, Schanda K, Gassner C, Deisenhammer F, Berger T, Lorenz E: Mutations in the gene for toll-like receptor 4 and multiple sclerosis. Tissue Antigens 2003, 61:85-88.

30. Sugimoto M, Yamaoka Y, Furuta T: Influence of interleukin polymorphisms on development of gastric cancer and peptic ulcer. World I Gastroenterol 2010, 16:1188-1200

31. Fernandez-Real JM, Broch M, Vendrell J, Gutierrez C, Casamitjana R, Pugeat M, Richart C, Ricart W: Interleukin-6 gene polymorphism and insulin sensitivity. Diabetes 2000, 49:517-520.

32. El-Omar EM, Carrington M, Chow WH, McColl KE, Bream JH, Young HA, Herrera J, Lissowska J, Yuan CC, Rothman N, et al: Interleukin-1 polymorphisms associated with increased risk of gastric cancer. Nature 2000, 404:398-402

33. Dolan S, Hollegaard M, Merialdi M, Betran A, Allen T, Abelow C, Nace J, Lin B, Khoury M, loannidis J: Synopsis of Preterm Birth Genetic Association Studies: The Preterm Birth Genetics Knowledge Base (PTBGene). Public Health Genomics 2010, 13:514-523.

34. van de Vosse E, Lichtenauer-Kaligis EGR, van Dissel JT, Ottenhoff THM: Genetic variations in the interleukin-12/interleukin-23 receptor (B1) chain, and implications for IL-12 and IL-23 receptor structure and function. Immunogenetics 2003, 54:817-829.

35. Namkung J-H, Lee J-E, Kim E, Kim S, Kim S, Shin E-S, Cho E-Y, Yang J-M: Association of single nucleotide polymorphisms in the IL-12 (IL-12A and B) and IL-12 receptor (IL-12R $\beta 1$ and $\beta 2$ ) genes and gene-gene interactions with atopic dermatitis in Koreans. J Dermatol Sci 2010, 57:199-206.

36. Hans-Hilger R: New Perspectives for the Elucidation of Genetic Disorders. Am J Hum Genet 2007, 81:199-207.

37. Ouchi N, Parker JL, Lugus JJ, Walsh K: Adipokines in inflammation and metabolic disease. Nat Rev Immunol 2011, 11:85-97.

38. Craft MK, Reed MJ: Immunologic changes in obesity. Crit Care Clin 2010, 26:629-631.

39. Donath MY, Shoelson SE: Type 2 diabetes as an inflammatory disease. Nat Rev Immunol 2011, 11:98-107.

doi:10.1186/1756-0500-5-69

Cite this article as: Pereyra et al:: Rapid multiplex high resolution melting method to analyze inflammatory related SNPs in preterm birth. BMC Research Notes 2012 5:69. 